\title{
LA-UR-17-23592
}

Approved for public release; distribution is unlimited.

Title: Survey of Neutron Generators for Active Interrogation

Author(s): $\quad$ Moss, Calvin Elroy

Myers, William L.

Sundby, Gary M.

Chichester, David L

Johnson, James $P$

Intended for: Report

Issued: 2017-05-02 
Disclaimer:

Los Alamos National Laboratory, an affirmative action/equal opportunity employer, is operated by the Los Alamos National Security, LLC for the National Nuclear Security Administration of the U.S. Department of Energy under contract DE-AC52-06NA25396. By approving this article, the publisher recognizes that the U.S. Government retains nonexclusive, royalty-free license to publish or reproduce the published form of this contribution, or to allow others to do so, for U.S. Government purposes. Los Alamos National Laboratory requests that the publisher identify this article as work performed under the auspices of the U.S. Department of Energy. Los Alamos National Laboratory strongly supports academic freedom and a researcher's right to publish; as an institution, however, the Laboratory does not endorse the viewpoint of a publication or guarantee its technical correctness. 


\section{Survey of Neutron Generators for Active Interrogation}

\section{Introduction}

Portable neutron generators contain compact linear accelerators that produce neutrons from the following nuclear reactions:

$$
\begin{aligned}
& \mathrm{D}+\mathrm{T} \rightarrow \mathrm{n}+{ }^{4} \mathrm{He}\left(\mathrm{E}_{\mathrm{n}}=14.1 \mathrm{MeV}\right) \\
& \mathrm{D}+\mathrm{D} \rightarrow \mathrm{n}+{ }^{3} \mathrm{He}\left(\mathrm{E}_{\mathrm{n}}=2.5 \mathrm{MeV}\right)
\end{aligned}
$$

Deuterons (D) or tritons (T) are accelerated onto a target that contains deuterium, tritium or a mixture of these isotopes. The accelerating voltages are typically in the range 80 to $200 \mathrm{kV}$. The deuterium-tritium (DT) reaction is used more often than the deuterium-deuterium (DD) reaction because the yield of the DT reaction is 50-100 times higher than that of the DD reaction. Neutrons produced from the DT reaction are emitted nearly isotropically, while neutrons from the DD reaction are peaked in the forward direction.

For portable systems, the accelerator is sealed in a vacuum enclosure called a neutron tube.

The tube contains an ion source, a target, a gas reservoir (getter), and ion optical elements. The tube, in turn, is enclosed in a metal housing, called the accelerator head, which contains a high voltage

transformer and other electronic control boards. The accelerator head is usually filled with a dielectric liquid (such as mineral oil or a fluorocarbon-based fluid) or gas (such as sulfur hexafluoride) to provide insulation for the high voltage transformer and neutron tube. The power supplies for the low-voltage input to the high voltage transformer and for the ion source and gas reservoir are located from 0.5 to 10 $\mathrm{m}$ away. The designs are simple and robust for portable use. The requirements for a portable neutron generator for interrogating SNM are given in Table 1. These specifications are for the P211 (discussed below), which is an old design and is no longer available.

Table 1. Portable Neutron Generator Specifications

\begin{tabular}{|l|l|}
\hline \multicolumn{1}{|c|}{ Key Parameters } & \multicolumn{1}{c|}{ Requirements } \\
\hline Neutron Output & $10^{6} \mathrm{n} / \mathrm{pulse}$ \\
\hline Energy & $14 \mathrm{MeV}$ \\
\hline Sync Pulse Output & To veto neutron data collection during pulse \\
\hline Intrapulse Output & Output Zero \\
\hline Lifetime & $500 \mathrm{~h}$ \\
\hline Pulse Range & Up to 100 pulses/s \\
\hline Pulse Width & $<10 \mu \mathrm{s}$ \\
\hline Power & Low enough for battery operation \\
\hline Size and Weight & Man transportable \\
\hline
\end{tabular}

The requirement that no neutrons be produced between pulses is needed because some of the active techniques for uranium look for die-away or beta-delayed neutrons between pulses. Many small 
neutron generators are commercially available for special applications such as borehole operations, bulk materials analysis, explosive detection, and chemical weapons. Some of these generators meet this requirement but some don't. Older-design portable neutron generators often used an analog transformer to activate the ion-source in the neutron tube; these systems were notorious for having a slow turn-off ramp, due to the presence of an effective resistor-capacitor (RC) circuit to bleed off voltage to the ion source. To compensate for this characteristic, neutron generators used in applications that required a 'zero-neutron-output' specification in between pulses also employed a high-voltage pulse transformer, so that any ions leaking from the ion source after the 'end' of a pulse did not experience a high-voltage gradient to permit neutron production. Newer generators, in contrast, often employ solidstate pulse transformers for controlling ion source performance; these generators have been shown to have inter-pulse turn-off times of less than 0.5 microseconds, with zero neutron production between pulses. For any candidate neutron generator being evaluated for the emergency response mission, tests will be required to determine if a neutron generator meets the zero-neutron requirement.

The following list of generators includes models that do not meet one or more of the above requirements but are included because there is a possibility that some of them could be modified to meet the requirements.

\section{Vendors}

Note: In nearly all cases specifying a DT neutron energy (14.1 MeV), a DD gas fill is also possible, which will produce $2.5 \mathrm{MeV}$ neutrons. Neutron yields in these cases can be expected to be between 50-100 times less than the quoted DT neutron yields.

\section{Thermo Fisher Scientific Inc}

Website: https://www.thermofisher.com/search/browse/results?customGroup=Neutron+Generators

\section{Models}

\section{P 211 (dual ion source - high-voltage pulse transformers, fluoroinert insulator)}

Specifications:

Neutron Yield

Neutron Energy

$1.0 \times 10^{6}$ neutrons $/ \mathrm{s}$

Pulsing

Minimum Pulse Width

$14 \mathrm{MeV}$

Lifetime

$10 \mathrm{~Hz}, 50 \mathrm{~Hz}, 100 \mathrm{~Hz}$, single shot

Power

$500 \mathrm{~h}$

$110 \mathrm{~V}, 1.3 \mathrm{~A}$

B 211 (updated version of P 211, fluoroinert or $S F_{6}$ insulating gas)

Specifications: similar to P 211 specifications 
MP 320 (lightweight, portable, $S_{6}$ insulating gas)

Specifications:

Neutron Yield

Neutron Energy

$1 \times 10^{8}$ neutrons/s

$14 \mathrm{MeV}$

Pulsing

Minimum Pulse Width

Continuous or $250 \mathrm{~Hz}$ to $20 \mathrm{kHz}$ continuous

Lifetime

$5 \mu \mathrm{s}$

Power

$1200 \mathrm{~h} @ 1 \times 10^{8} \mathrm{n} / \mathrm{s}$

Total Weight

$<50 \mathrm{~W}$, may be operated from battery

Control

$12 \mathrm{~kg}$ (26.5 lbs)

Digital control

B 320 (borehole tool, $S_{F_{6}}$ insulating gas)

Specifications:

Neutron Yield

Neutron Energy

$1 \times 10^{8}$ neutrons $/ \mathrm{s}$

Duty cycle

$14 \mathrm{MeV}$

Diameter

$10 \%$

1.69 in

P 385 (middle weight, portable, $\mathrm{SF}_{6}$ insulating gas)

Specifications:

Neutron Yield

Neutron Energy

Nominal $3.0 \times 10^{8} \mathrm{n} / \mathrm{s}$, Max $5.0 \times 10^{8} \mathrm{n} / \mathrm{s}$

Pulsing

$14 \mathrm{MeV}$

Minimum Pulse Width

Continuous or $250 \mathrm{~Hz}$ to $20 \mathrm{kHz}$

Lifetime

$5 \mu \mathrm{s}$

Duty Cycle

$1500 \mathrm{~h}$ at $3.0 \times 10^{8} \mathrm{n} / \mathrm{s}, 4500 \mathrm{~h}$ at $10^{8} \mathrm{n} / \mathrm{s}$

Head Dimensions

$5 \%$ to $100 \%$

Head Weight

$102 \mathrm{~mm}$ dia. $\times 686 \mathrm{~mm}$ length

Power

$17 \mathrm{~kg}(37.4 \mathrm{lb})$

$\sim 75 \mathrm{~W}$

API 120 (portable, associated particle imaging, SF $_{6}$ insulating gas)

Specifications:

Neutron Yield

Neutron Energy

$2.0 \times 10^{7} \mathrm{n} / \mathrm{s}$

Pulsing

$14 \mathrm{MeV}$

Lifetime

Continuous only

Total Weight

Power

$1200 \mathrm{~h}$ at $1 \times 10^{7} \mathrm{n} / \mathrm{s}$

$15 \mathrm{~kg}(33 \mathrm{lb})$

$<50 \mathrm{~W}$ 
Specifications:

Neutron Yield

Neutron Energy

Pulsing

Lifetime

Total Weight

Control

$2.0 \times 10^{10} \mathrm{n} / \mathrm{s} \max$

$14 \mathrm{MeV}$

Continuous only

$1000 \mathrm{~h}$ at $1 \times 10^{10} \mathrm{n} / \mathrm{s}$

$1000 \mathrm{~kg}$

Digital control

\section{SODERN}

Website: http://www.sodern.fr

Models

Genie 16 (Portable, SF $_{6}$ insulating gas)

Specifications:

Neutron Yield

Neutron Energy

up to $2 \times 10^{8}$ neutrons/s

Pulsing

$14 \mathrm{MeV}$

Minimum Pulse Width

up to $5 \mathrm{kHz}$ or continuous

Lifetime

$<5 \mu \mathrm{s}$

Head Dimensions

$4000 \mathrm{~h}$ at $1 \times 10^{8} \mathrm{n} / \mathrm{s}, 8000 \mathrm{~h}$ at $5 \times 10^{7} \mathrm{n} / \mathrm{s}$

Head Weight

$<104 \mathrm{~mm}$ dia. $x<740 \mathrm{~mm}$ length

Control Rack Weight

Power Supply Weight

$8 \mathrm{~kg}$

$10 \mathrm{~kg}$

$10 \mathrm{~kg}$

Power

$230 \mathrm{VAC} / 50 \mathrm{~Hz}(16 \mathrm{~A})$ or $115 \mathrm{VAC} / 60 \mathrm{~Hz}$

\section{Genie 35 (Fixed system, oil insulator)}

Specifications:

Neutron Yield

Neutron Energy

Pulsing

Minimum Pulse Width

Lifetime

up to $10^{10}$ neutrons/s

$14 \mathrm{MeV}$

up to $5 \mathrm{kHz}$ or continuous

$10 \mu \mathrm{s}$

$2000 \mathrm{~h}$ at $2 \times 10^{9} \mathrm{n} / \mathrm{s}$

Head Dimensions

$<150 \mathrm{~mm}$ dia. $x<900 \mathrm{~mm}$ length

Power

$230 \mathrm{VAC} / 50 \mathrm{~Hz}(16 \mathrm{~A})$

\section{Phoenix Nuclear Labs}

Website: http://phoenixnuclearlabs.com/product/low-yield-neutron-generator/ 


\section{Models}

\section{Ultra Compact Generator}

Specifications:

Neutron Yield

Neutron Energy

$1 \times 10^{9}$ to $5 \times 10^{10}$ neutrons $/ \mathrm{s}$

Pulsing

$2.5 \mathrm{MeV}$

Lifetime

Pulsed or continuous

Maximum Beam Current

$10,000 \mathrm{~h}$

Maximum Accelerating Voltage $300 \mathrm{kV}$

Head Dimensions

$100 \times 35 \times 35 \mathrm{~cm}$

Head Weight

$150 \mathrm{~kg}$

Supporting Equipment Dims. $50 \times 80 \mathrm{~cm}$

Supporting Equipment Weight $100 \mathrm{~kg}$

Power

480 VAC

\section{Starfire Industries}

Website: starfireindustries.com

\section{Models}

nGen-300C (battery powered)

Specifications:

Neutron Yield

Neutron Energy

$10^{7} \mathrm{n} / \mathrm{s} @ 4 \%$ duty factor

Ion Source Type

$2.5 \mathrm{MeV}$

Pulse Rate

Electrodeless RF

Pulse Width

Single shot to $200 \mathrm{kHz}$

Pulse Rise/Fall Time

5-1000 $\mu \mathrm{s}$

Nominal Duty Factor

$<5 \mu \mathrm{s}$

Dark Current between Pulses

$5 \%$

Operating Voltage

Power Requirements

None

up to $140 \mathrm{kV}$

$400 \mathrm{~W}$

Neutron Source Dimensions $\quad 3$ " OD $\times 18$ " L

Neutron Source Weight $10 \mathrm{lbs}$

Supporting Hardware Dims. 12 " W $\times 12$ " $\mathrm{H} \times 12$ " L

Supporting Hardware Weight 20 lbs with battery

\section{Schlumberger}

Website: www.slb.com/oilfield 
Models

RSTPro (well logging tool)

Specifications:

DT Neutron Yield $\quad 3 \times 10^{8}$ neutrons $/ \mathrm{sec}$

Dimensions

Slim Tool: 1.710 in dia $\times 23.1 \mathrm{ft}$ length

Focused Tool: 2.505 in dia $\times 22.2 \mathrm{ft}$ length

Flasked Tool: 2.125 in dia $\times 33.7 \mathrm{ft}$ length

Adelphi Technology, Inc.

Website: www.adelphitech.com

Models

DT109-DT110 (neutron generator)

Specifications:

DT Neutron Yield $\quad 1 \times 10^{10}$ neutrons/sec maximum

Neutron Energy

$14.1 \mathrm{MeV}$

Pulsing

Power

$\geq 100 \mu$ s to continuous, requires TTL for pulsing

Lifetime $500 \mathrm{~W}, 110 \mathrm{~V} \mathrm{AC}$, battery power feasible

Several thousand hours

DT108API (associated particle imaging)

Specifications:

Neutron Energy

Pulsing

Power

Lifetime

$14 \mathrm{MeV}$

Continuous

Head Weight

120 VAC, 20 A circuit

$2000 \mathrm{~h}$

$50 \mathrm{lbs}$

Control \& Power Rack Weight $100 \mathrm{lbs}$

Heat Exchanger Weight $30 \mathrm{lbs}$

Total Weight $180 \mathrm{lbs}$

\section{All-Russia Research Institute of Automatics (VNIIIA)}

Website: http://vniia.ru/eng/ng/element.html

Models

ING-013 (vacuum neutron tube)

Specifications: 


$\begin{array}{ll}\text { Neutron Yield } & \text { up to } 5 \times 10^{9} \text { neutrons/s } \\ \text { Neutron Energy } & 14 \mathrm{MeV} \\ \text { Pulse Width } & 0.8 \text { to } 1.2 \mu \mathrm{s} \\ \text { Pulsing Frequency } & 1 \text { to } 50 \mathrm{~Hz} \\ \text { Lifetime } & 1600 \mathrm{~h} \mathrm{at} 10^{8} \text { neutrons } / \mathrm{s} \\ \text { Power } & 220 \mathrm{~V}, 50 \mathrm{~Hz}, 500 \mathrm{~W} \mathrm{max} \\ \text { Head Dimensions } & 130 \mathrm{~mm} \mathrm{dia} \times 1000 \mathrm{~mm} \text { length } \\ \text { Control } & \text { PC }\end{array}$

ING-03 (vacuum neutron tube)

Specifications:

Neutron Yield

Neutron Energy

Pulse Width

up to $3 \times 10^{9}$ neutrons $/ \mathrm{s}$

$14 \mathrm{MeV}$

Pulsing Frequency

$1.2 \mu \mathrm{s}$

Lifetime

1 to $30 \mathrm{~Hz}$

Power $1600 \mathrm{~h}$ at $10^{8}$ neutrons/s

Head Dimensions $220 \mathrm{~V}, 50 \mathrm{~Hz}, 100 \mathrm{~W}$ max

Control

$130 \mathrm{~mm}$ dia $\times 950 \mathrm{~mm}$ length

PC

\title{
ING-031 (vacuum neutron tube)
}

Specifications:

Neutron Yield

Neutron Energy

up to $2 \times 10^{10}$ neutrons/s

Pulse Width

$14 \mathrm{MeV}$

Pulsing Frequency

$1.2 \mu \mathrm{s}$

Lifetime

1 to $100 \mathrm{~Hz}$

Power $1600 \mathrm{~h}$ at $10^{8}$ neutrons/s

Head Dimensions $220 \mathrm{~V}, 50 \mathrm{~Hz}, 700 \mathrm{~W}$ max

Control $130 \mathrm{~mm}$ dia $\times 950 \mathrm{~mm}$ length

PC

\author{
ING-07 (gas-filled neutron tube) \\ Specifications: \\ Neutron Yield \\ Neutron Energy \\ Pulse Width \\ up to $10^{9}$ neutrons/s \\ $14 \mathrm{MeV}$ \\ Pulsing Frequency \\ 20 to $100 \mu \mathrm{s}$ \\ Lifetime \\ 400 to $10000 \mathrm{~Hz}$ or continuous \\ Power \\ $500 \mathrm{~h}$ \\ Head Dimensions \\ $110 / 220 \mathrm{~V}, 50 / 60 \mathrm{~Hz}, 200 \mathrm{~W}$ max \\ Control \\ $190 \mathrm{~mm}$ dia $\times 440 \mathrm{~mm}$ length \\ PC
}


Specifications:

Neutron Yield

Neutron Energy

Pulse Width

up to $3 \times 10^{8}$ neutrons $/ \mathrm{s}$

$14 \mathrm{MeV}$

Pulsing Frequency

20 to $100 \mu \mathrm{s}$

Lifetime

400 to $10000 \mathrm{~Hz}$ or continuous

Power $300 \mathrm{~h}$

Head Dimensions

$110 / 220 \mathrm{~V}, 50 / 60 \mathrm{~Hz}, 120 \mathrm{~W} \max$

Control

$70 \mathrm{~mm}$ dia $\times 480 \mathrm{~mm}$ length

PC

ING-27 (gas-filled neutron tube, associated particle imaging)

Specifications:

Neutron Yield

up to $10^{8}$ neutrons/s

Neutron Energy

$14 \mathrm{MeV}$

Pulsing Frequency

Continuous

Number of pixels

at least 9

Lifetime

$100 \mathrm{~h} @ 5 \times 10^{7}$ neutrons $/ \mathrm{s}$

Head Dimensions ( $\mathrm{mm}$ )

$220 \times 130 \times 179$

PS and Control Dimensions (mm) $279 \times 193 \times 94$

Head Weight

$7.0 \mathrm{~kg}$

PS and Control Weight

$3.0 \mathrm{~kg}$

\section{ING-14 (gas-filled neutron tube)}

Specifications:

Neutron Yield

Neutron Energy

up to $2 \times 10^{10}$ neutrons/s

Pulsing Frequency

$14 \mathrm{MeV}$

Lifetime

Continuous

Power

$300 \mathrm{~h}$

Head Dimensions

Head Weight

Control

$110 / 220 \mathrm{~V}, 50 / 60 \mathrm{~Hz}, 600 \mathrm{~W} \max$

$290 \mathrm{~mm}$ dia $\times 840 \mathrm{~mm}$ length

$60 \mathrm{~kg}$

$\mathrm{PC}$

\section{Xi'an Petroleum Exploration Instrument Complex}

Borehole neutron generators

Reference: Peng Hu, Ke Xianda, and Lu Jishen, "Applications of Neutron Generators in Well Logging and Other Fields," Nuclear Electronics and Detection Technology 13, 137 (1993) in Chinese. 


\section{China Institute of Atomic Energy}

Generator for well logging

Reference: Xiao Kunxiang, Ai Jun, Shi Guijuan, Xiang Chuan, and Mei Lin, "Development of Small Neutron Generators for Well Logging," Nuclear Physics Review 29, 81 (2012) in Chinese.

\section{Northeast Normal University}

References:

Gang Li, Zhong-Shuai Zhang, Qian Chi, and Lin-Mao Liu, "50 m Diameter Digital DC/pulse Neutron Generator for Subcritical Reactor Test," Nucl. Instr. Meth. B 290, 64 (2012).

Dong Aiping, Li Wenjie, Wang Qiang, and Chen Baojiu, "A Sealed Tube Neutron Generator with Neutron Yield > $1.5 \times 10^{10} \mathrm{n} / \mathrm{s}$," http://en.cnki.com.cn/Article en/CJFDTOTAL-HJSU506.003.htm.

\section{Lanzhou University}

Engineering Research Center for Neutron Application Technology

Website: http://en.lzu.edu.cn/content/88.html

\section{China Academy of Engineering Physics}

Compact Pulsed Neutron Generator

Reference: Zhen Yang, "Performance Improvement of a Compact Pulsed Neutron Generator with a Vacuum Arc Ion Source," IEEE Power Modulator and High Voltage Conference, San Francisco, 5-9 July 2016.

\section{Discussion and Conclusions}

Some of these commercially available generators meet all of the requirements in Table 1, but there are other concerns. Most generators containing $\mathrm{SF}_{6}$ will be required to have the $\mathrm{SF}_{6}$ gas removed for shipping because of DOT regulations. However, Thermo Fisher has a DOT exemption. The P211 and B211 from Thermo Fisher meet the requirements listed in Table 1, but they are old designs and are no longer offered for sale. Also, they require 15 minutes or more of warmup before neutron output is available, and they lack a modern digital control. The nGen-300C from Starfire Industries is interesting because it is a portable system, but it uses the DD reaction for $2.5 \mathrm{MeV}$ neutrons, which are not as penetrating as the $14 \mathrm{MeV}$ neutrons from the DT reaction. The MP 320 from Thermo Fisher is another portable system, but the minimum pulse rate is $250 \mathrm{~Hz}$, which is too fast for measurement of delayed neutrons and re-interrogation by delayed neutrons between pulses. The Genie 16 from Sodern (from France) probably meets the requirements, but the required power is probably too high for battery operation. The generators from Russia and China may be difficult to purchase, and service may not be available.

The power required by some of these generators is low enough that batteries can be used. The portable units, nGen-300C and the MP320, could easily be operated with batteries. Other generators with low power requirements, as specified in the above vendors list, could possibly be operated with reason size batteries. The batteries do not need to be internal to the generator, but can be in a separate package. The availability of high capacity lithium batteries with sophisticated safety circuits makes battery operation more possible now than when lead acid batteries were used. 
The best path forward probably requires working with vendors of the existing systems. If Starfire Industries could be persuaded to put tritium in their nGen-300C generator, possibly in collaboration with a national laboratory, this would provide the $14-\mathrm{MeV}$ neutrons needed. Another possibility is a modification of the Thermo Fisher MP 320 to run at 50 to $100 \mathrm{~Hz}$. More discussions with these vendors, and possibly others, are required to determine their interest and possible costs. 
Appendix. Other Considerations for Emergency Response

- Start-up time, from storage to being ready for operation

- Recommended regular operating frequency

- Temperature operating range

- Humidity operating range

- Vibration limits for shipping, etc.

- Dust susceptibility

- Associated x-ray production

- Electromagnetic emissions

- Electromagnetic susceptibility

- Electronic grounding

- Orientation limitations (mostly only relevant for the liquid filled systems, where the presence of a bubble in the liquid can be a problem)

- Maximum single-use on time (found in systems with poor cooling, where they tend to heat up) 